\title{
Avaliação de Metologias de Baixo Custo para Analisar Desgaste e Atrito EM Componentes de PNEUS
}

\author{
T. Vieira ${ }^{1}$, R. P. Ferreira ${ }^{2}$, A. K. Kuchiishi ${ }^{1}$, L. L. B. Bernucci ${ }^{1}$, D. K. Tanaka ${ }^{2}$ \\ ${ }^{1}$ Laboratório de Tecnologia de Pavimentação - Escola Politécnica da USP \\ ${ }^{2}$ Laboratório de Fenômenos de Superfície - Escola Politécnica da USP \\ E-mails: tiagovr@gmail.com, renata.pme@gmail.com, kazuo.andre@gmail.com, \\ $\underline{\text { liedi@usp.br, dktanaka@usp.br }}$
}

\section{RESUMO}

Pneus tem uma grande variedade de aplicações na indústria automotiva. Entender sua complexa interação com o pavimento é fundamental para melhorar os projetos e processo de fabricação. Devido a sua complexa interação e a natureza viscoelástica da borracha, é difícil e custoso avaliar relevantes fenômenos que ocorrem na área de contato pneu/pavimento. $\mathrm{O}$ desempenho do atrito em pneus é relacionado a dois mecanismos distintos: histerese e adesão. De acordo com a formulação clássica do atrito de borrachas, ambos os termos são independentes, e então, um pode ser suprimido para avaliar o outro termo. Outro efeito conhecido resultado do contato pneu/pavimento é a formação das ondas de Schallamach, indicativo do processo de desgaste. O objetivo deste artigo é avaliar métodos de baixo custo para medir atrito e desgaste em pneus. Testes laboratoriais de atrito foram realizados utilizando Pendulo Britânico modificado e a componente adesiva do atrito foi avaliada separadamente. Testes de desgaste foram realizados em tambor rotativo e a superfície da amostra foi analisada em microscópio ótico. Adicionalmente foi avaliada a energia de superfície dos compostos de borracha.

\section{INTRODUÇÃO}

A superfície do pavimento asfáltico representa o meio de contato direto com os veículos que utilizam as vias de tráfego rodoviário. Esta, por sua vez, possui um papel fundamental no desempenho da infraestrutura das vias, estando intimamente relacionada com o desempenho dos pneus veiculares, que, em conjunto, garantem segurança no transporte, eficiência, resistência ao escorregamento e baixo consumo de combustível.

A construção de vias com características impróprias de textura implicam em maior taxa de desgaste dos pneus. Avaliando-se crescimento econômico e social em função da infraestrutura de transportes [1] torna-se evidente que estudos mais aprofundados referentes à superfície de pavimentos devem ser realizados. A demanda estimada de pneus para 2015 é de 3,3 bilhões de unidades [2] e, por não ser um material biodegradável, seu desgaste significa desperdício e consequentemente uma preocupação de questão ambiental.

Além da importância da superfície do revestimento asfáltico, avaliar características do pneu é fundamental, uma vez que este representa a interação direta entre os veículos e as vias sobre 
as quais circulam. Assim, a análise de parâmetros como atrito e desgaste de borracha pode ser considerada essencial econômica e ambientalmente. A preocupação com a qualidade de desempenho dos pneus pode ser destacada na União Europeia, na qual os pneus são regulamentados e etiquetados [3]. A regulamentação classifica cada pneu de acordo com três características distintas: (i) Eficiência no Consumo de Combustível, (ii) Resistência a aquaplanagem e (iii) Ruído Externo ao Rolamento, aspectos estes fundamentais para a caracterização de borrachas.

Este artigo tem como enfoque a avaliação de métodos de baixo custo para borrachas, analisando o atrito e o desgaste das mesmas. Dentro deste universo, para um pneu ser considerado de bom desempenho, deve apresentar coeficiente de atrito mais elevado, o que proporciona segurança, e desgaste reduzido, de modo que sua vida útil seja maximizada. Serão avaliados quatro métodos: Pêndulo Britânico, avaliação da energia de superfície, abrasão por tambor rotativo, e estimativa do comprimento de onda do padrão de abrasão.

\section{REVISÃO}

Para a elaboração deste artigo, foi utilizado o modelo de atrito formulado por Moore [4], que define o atrito como a combinação de duas variáveis matematicamente independentes: a histerese e a adesão. A primeira está relacionada com a dissipação de energia que ocorre devido à deformação defasada da borracha, quando mecanicamente solicitada. Isto ocorre em virtude das propriedades viscoelásticas da borracha, bem como da textura superficial do pavimento e distribuição relativa de asperezas durante o contato pneu-pavimento. A segunda componente, por sua vez, está relacionada com as forças adesivas que atraem uma superfície à outra e depende também da capacidade adesiva que o tribosistema em análise possui. A adesão pode ser classificada em cinco categorias distintas que serão brevemente explicadas: (i) química, (ii) dispersiva, (iii) eletrostática, (iv) difusiva e (v) micro-histerética.

A adesão química é definida como a atração das duas superfícies ocasionada por troca de elétrons entre as mesmas em ligações iônicas, ou compartilhamento de elétrons em ligações covalentes [5]. A segunda, dispersiva, está relacionada com as forças intermoleculares de Van der Waals existentes no contato pneu-pavimento que também contribuem para manter as superfícies juntas [6]. A eletrostática corresponde à atração dos corpos por passagem de elétrons, gerando uma superfície negativa e outra positiva que, consequentemente, tendem a manter o contato entre si [5]. A adesão difusiva, por sua vez, relaciona-se com a interpenetração das cadeias poliméricas quando uma superfície é solúvel à outra [5] e, finalmente, por micro-histerese a atração dos dois corpos é ocasionada pela histerese da borracha que ocorre em uma micro-escala do contato.

As duas componentes adesivas mais importantes no contato pneu-pavimento são a dispersiva e eletrostática [5]. A segunda delas, por ser dependente da umidade, não foi considerada nas análises de adesão realizadas, restando somente a componente dispersiva. Enquanto alguns autores consideram que a influência da adesão é insignificante $[7 ; 8]$, outros afirmam que esta componente é totalmente desprezível $[9 ; 5]$. Para o propósito deste artigo, a adesão não será negligenciada.

O contato inicial entre a borracha e a superfície, o contra-corpo, rígida, ambas sujeitas à ação de forças adesivas, corresponde a uma fase inicial denominada stick. O movimento relativo entre as superfícies pode gerar tensões no mesmo sentido do movimento, podendo superar a 
capacidade do sistema se manter unido por adesão, entrando assim na fase de separação. Esta, por sua vez, é dividida em dois fenômenos diferentes: stick-slip, quando tensões de cisalhamento entre as superfícies causam a separação das mesmas, e stick-snap, quando forças normais à superfície de contato causam a separação. Quando isto ocorre, um par de novas superfícies é criado, par este que se mantinha em contato por forças adesivas. A energia necessária para garantir essa separação é denominada energia de superfície, que pode ser entendida como a quantidade de energia necessária para a criação de uma unidade de área [10]. A energia de superfície foi utilizada como mais um parâmetro de análise das características adesivas existentes no contato pneu-pavimento. Ainda é possível acrescentar que a análise de energia de superfície serve de alternativa de avaliação, de modo a corroborar os dados de atrito obtidos pelo Pêndulo Britânico [11].

Juntamente com o fenômeno de instabilidade superficial, o efeito de stick-slip também contribui para a formação de ondas de Schallamach [12], primeiramente evidenciadas por Adolf Schallamach em 1952 [13]. O padrão de ondas encontrado na superfície das amostras de borracha, Figura 1, é representativo do desgaste da mesma, incluindo pneus industrializados [14;13]. A Figura 2 apresenta a formação deste mesmo padrão de abrasão na banda de rodagem de um pneumático.

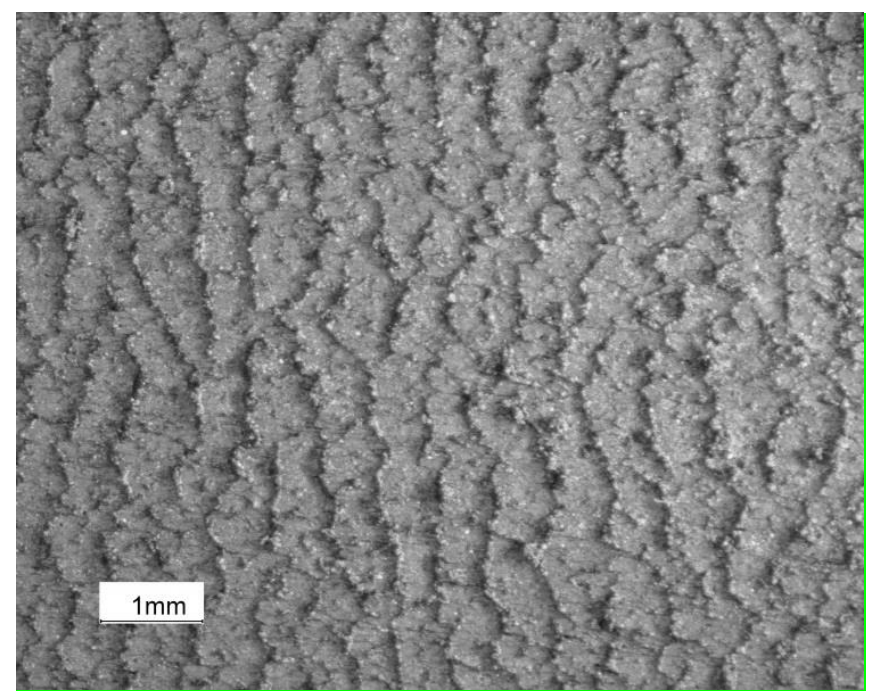

Figura 1 - Ondas de Schallamach presenciadas nas amostras de borracha após ensaio de abrasão

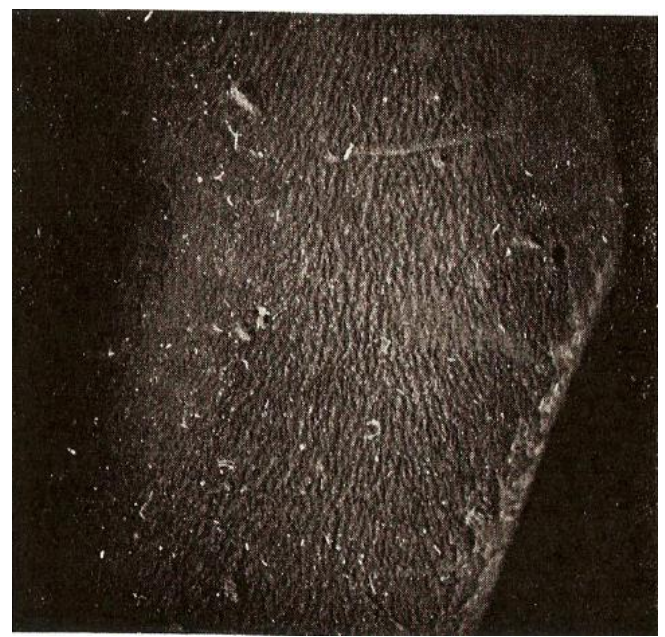

Figura 2 - Ondas de Schallamach presenciadas em pneus na banda de rodagem [13] 
As taxas de desgaste obtidas pelos ensaios de abrasão [15] podem ser correlacionadas com o padrão de espaçamento de ondas de Schallamach. Tais espaçamentos e amplitudes de onda são diretamente proporcionais à severidade de abrasão [16;17]. Da Figura 3, observa-se que os dados obtidos por FUKAHORI e YAMAZAKI [18], e UCHIYAMA e ISHINO [19], revelam uma relação direta entre taxa desgaste e o espaçamento entre onda.

a)

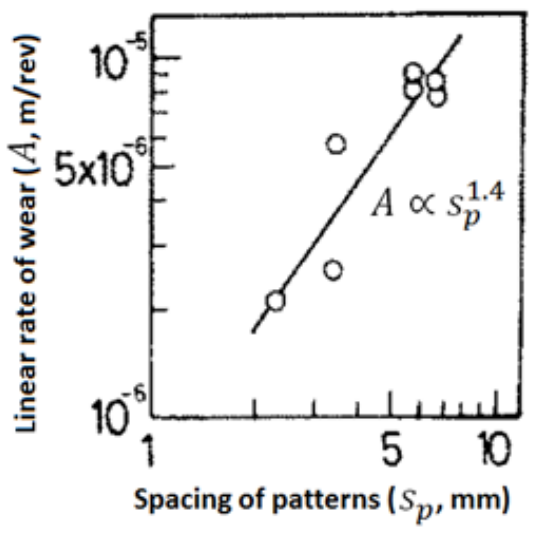

b)

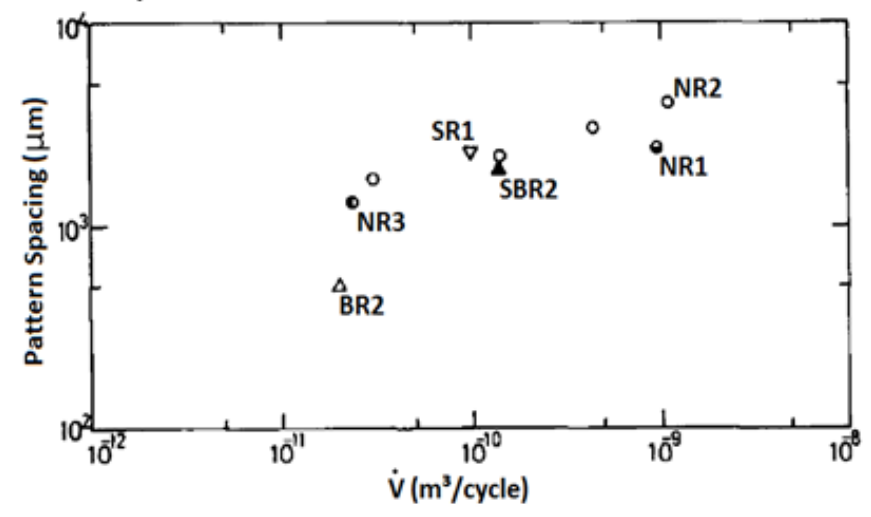

Figura 3 - Relação linear entre taxa de desgaste e espaçamento dos padrões de onda [19] em a) e relação diretamente proporcional entre as mesmas variáveis [18] em b). Ambos com diferentes compostos de borracha

Além disso, a Equação 1 confirma a proporcionalidade entre taxa de desgaste, $\dot{V}$, e o espaçamento do padrão de ondas, $s_{p}$, [18], sendo $k$ e $n$ constantes da equação.

$$
\dot{V}=k \cdot s_{p}^{n}
$$

Equação 1 - Relação entre taxa de desgaste e espaçamento do padrão de ondas

Finalmente, a Figura 4 apresenta um modelo conceitual da análise deste trabalho, onde se deseja quantificar/qualificar o desempenho de um pneu utilizando atrito e desgaste através de métodos tradicionais (Pêndulo Britânico e ensaio DIN por tambor rotativo) e métodos alternativos (método da gota e comprimento de onda), item 2. Os métodos alternativos serão conflitados para ver se são representantes reais de análise de desempenho. Como adicional, também será verificado se há alguma relação entre o comprimento das ondas de abrasão com os valores de energia de superfície, visto que nas ondas há a formação de novas áreas.

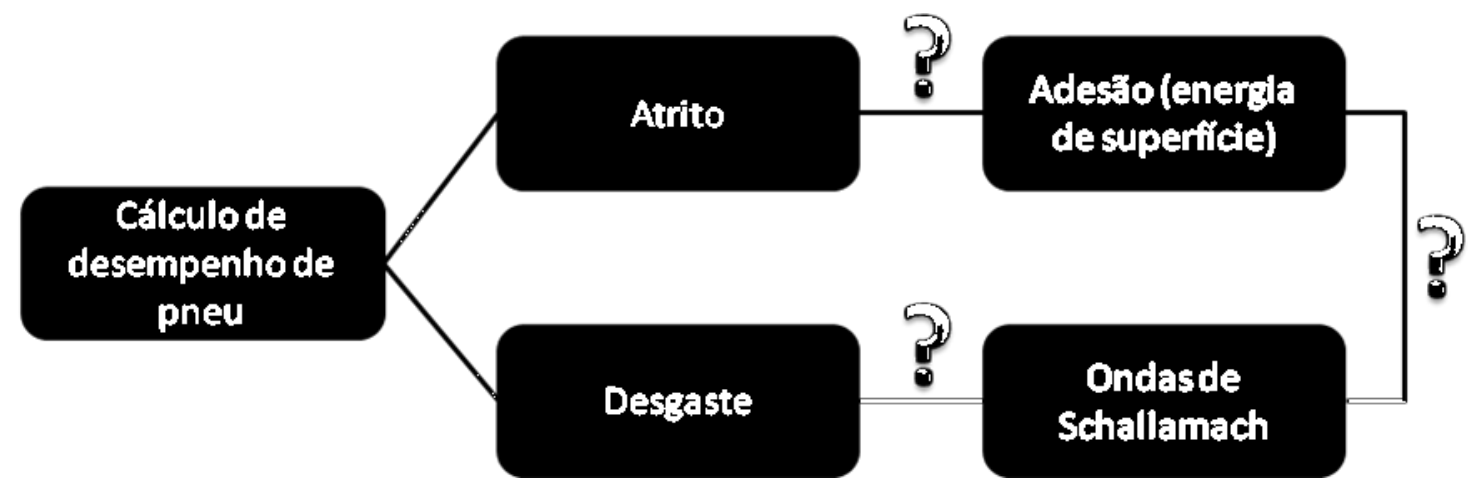

Figura 4 - Modelo conceitual de análise 


\section{METODOLOGIA}

Tendo em vista a necessidade de se medir atrito, desgaste e energia de superfície, foram-se pensados ensaios de baixo custo e tradicionais na indústria da borracha, os quais estão mais bem detalhados nos subitens abaixo. Observa-se que em todos os testes seguiram um planejamento para se evitar possíveis erros de ordem sistemática e, deste modo, os ensaios foram aleatorizados completamente.

\subsection{Atritos (lixa e pavimento)}

Com o intuito de se avaliar o atrito, foi realizado o ensaio padrão de Pêndulo Britânico [20], de baixo custo operacional e facilidade de manuseio. Considerado um equipamento bastante difundido na área de transportes para análise de atrito, o Pêndulo Britânico é utilizado para se avaliar a microtextura do pavimento. Fatores como temperatura, tipos de borracha, tipos de contra-corpo e lubrificantes foram laboratorialmente controlados de modo a se garantir a confiabilidade dos dados obtidos.

Os ensaios foram realizados no Laboratório de Tecnologia de Pavimentação da Universidade de São Paulo, sendo utilizados dois contra-corpos rígidos distintos, o pavimento asfáltico e a lixa para ensaio de abrasão. Os dados de Pêndulo Britânico com pavimento asfáltico, na Figura 5, são provenientes de Vieira [21], e foram realizados com diferentes combinações entre temperaturas, borrachas, lubrificantes e amostras de pavimento. Com o objetivo de se realizar ensaios confirmatórios, foram utilizadas as mesmas borrachas substituindo o pavimento asfáltico pela lixa do ensaio de abrasão por cilindro rotativo [15], item 2.3, efetuando, desta vez, ensaio a seco.

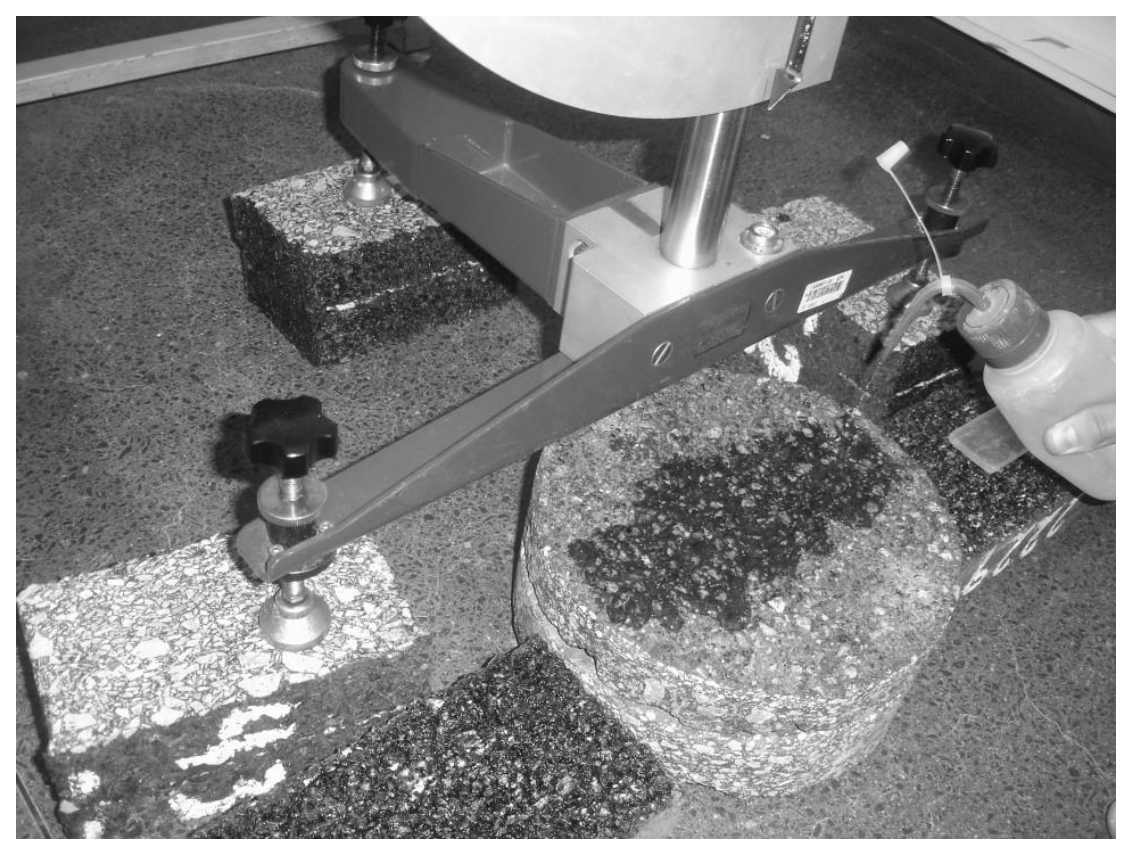

Figura 5 - Ensaio com o Pêndulo Britânico com pavimento asfáltico

2.2. Energia de superfície 
Os ensaios de energia de superfície, através do método da gota séssil, foram realizados no Laboratório de Plasmas Tecnológicos da Universidade Estadual Paulista Júlio de Mesquita Filho (UNESP). De forma a melhor atender aos requisitos físicos do equipamento ilustrado na Figura 6, como posicionamento e manuseio dos corpos de prova, foram utilizadas amostras cilíndricas das mesmas borrachas.

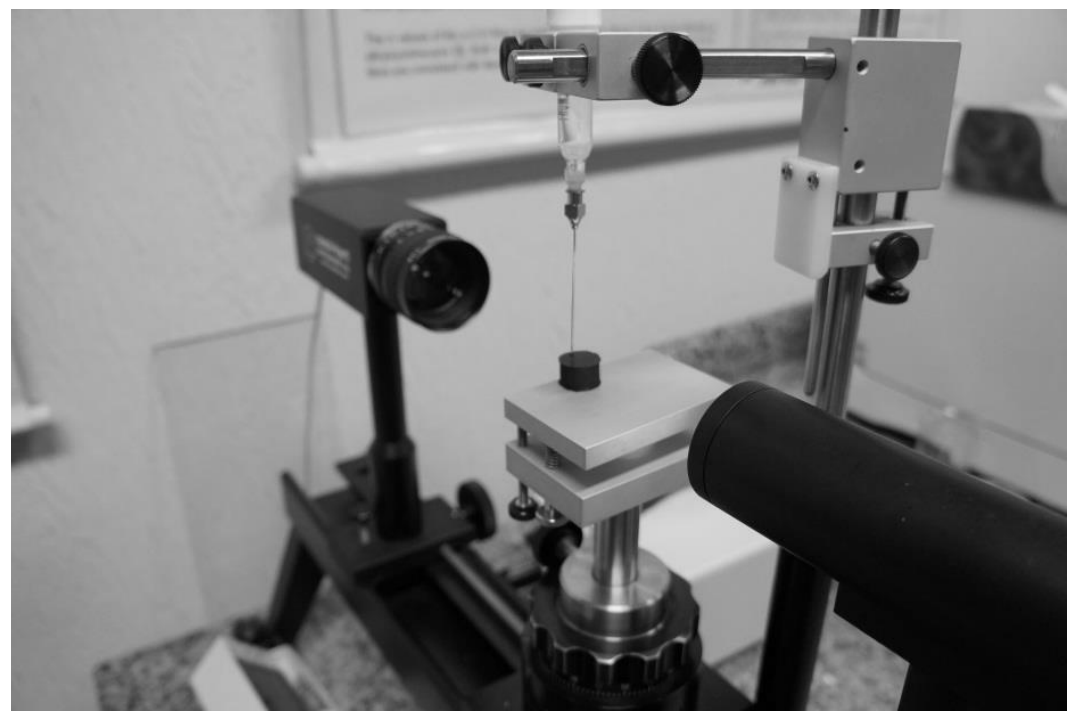

Figura 6 - Equipamento utilizado para ensaio de energia de superfície

Para a realização do ensaio foram utilizados dois fluidos distintos, água e diodometano. As amostras de borracha, além de higienizadas com álcool isopropílico e água destilada, foram submetidas a um banho ultrassônico, Figura 7, para que qualquer impureza superficial fosse removida antes de se iniciar o ensaio. Os valores de energia de superfície, obtidos utilizando o ângulo de contato por histerese da gota com a superfície da borracha, são medidos em Dyn*cm. Esses dados podem ser interpretados como a quantidade de energia necessária para a formação de uma nova área unitária de superfície.

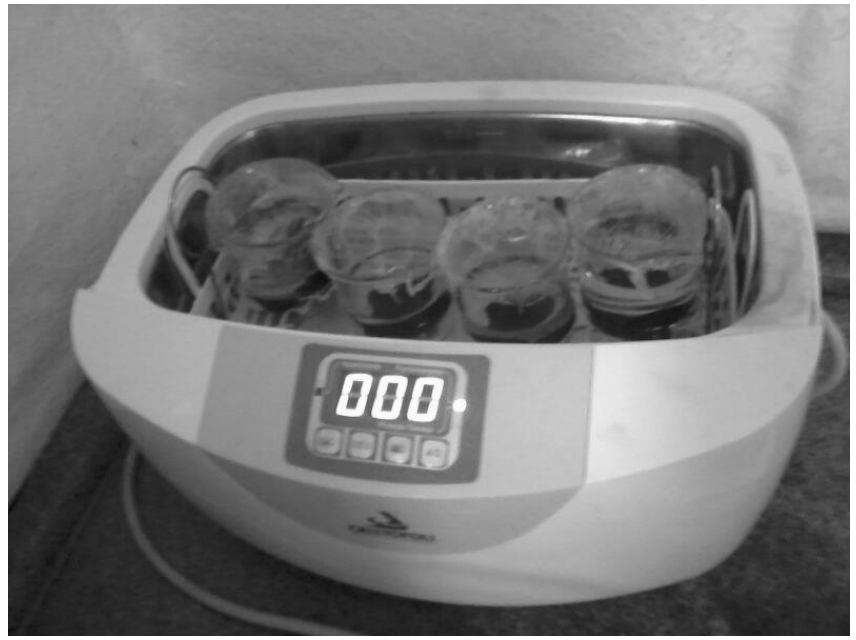

Figura 7 - Banho ultrassônico nas quatro amostras de borracha

\subsection{Desgaste}


Para se calcular o desgaste, foi pensado num método simples, usual na indústria da borracha, normalizado e relativamente barato se comparado com ensaios in locu de desgaste de pneus. Deste modo, escolheu-se o ensaio de abrasão por cilindro rotativo, Figura 8, seguindo a norma ASTM [15], realizado no Laboratório de Fenômenos de Superfície (LFS) da Universidade de São Paulo.

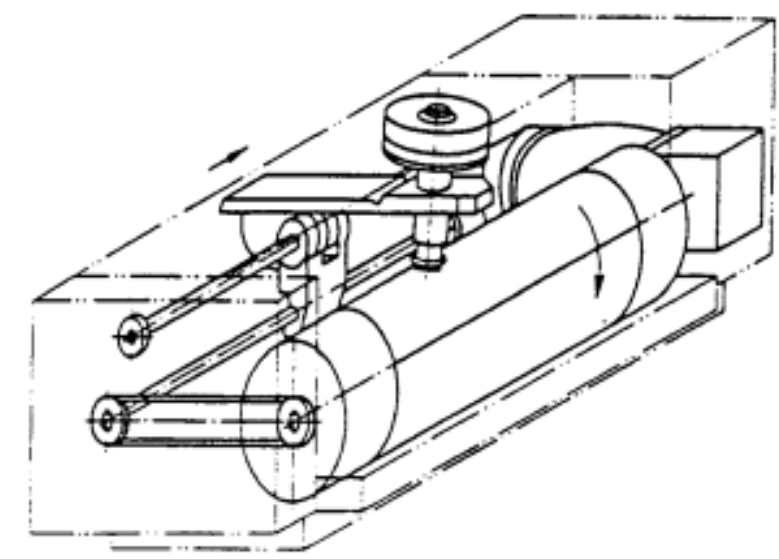

Figura 8 - Máquina utilizada para o ensaio de desgaste [15]

O resultado deste ensaio é a perda volumétrica através abrasão (A) da borracha, calculada através da Equação 2, dado em $\mathrm{mm}^{3}$, onde $\Delta m_{t}$ é a perda de massa do corpo de prova em miligramas, $S_{o}$ abrasividade normal da borracha padrão (200 mg), $d_{t}$ a densidade do corpo de prova em $\mathrm{mg} / \mathrm{m}^{3}$ e $S$ a abrasividade real da borracha padrão em miligramas. Observa-se que é necessário o valor da densidade da borracha e para obtê-la utilizaram-se medidas de massa seca e úmida.

Equação 2 - Perda de massa por abrasão (ASTM D5963)

$$
A=\frac{\Delta m_{t} * S_{o}}{d_{t} * S}
$$

\subsection{Comprimento de onda}

Microscópio óptico foi utilizado para analisar a superfície de desgaste após o ensaio do item 2.3, necessário para o cálculo do comprimento de onda. Todas as superfícies após o ensaio de abrasão demonstraram o aparecimento das ondas de Schallamach.

O comprimento de onda é calculado a partir de um comprimento específico medido pelo número de ondas, como descrito por Ferreira [22]. Todavia em vez de empregar um comprimento específico de $1,5 \mathrm{~mm}$, foram utilizados $7,5 \mathrm{~mm}$, devido ao intervalo menor já possuir comprimento suficiente para conter certo número de ondas, de modo que o erro no cálculo não seja significante. 


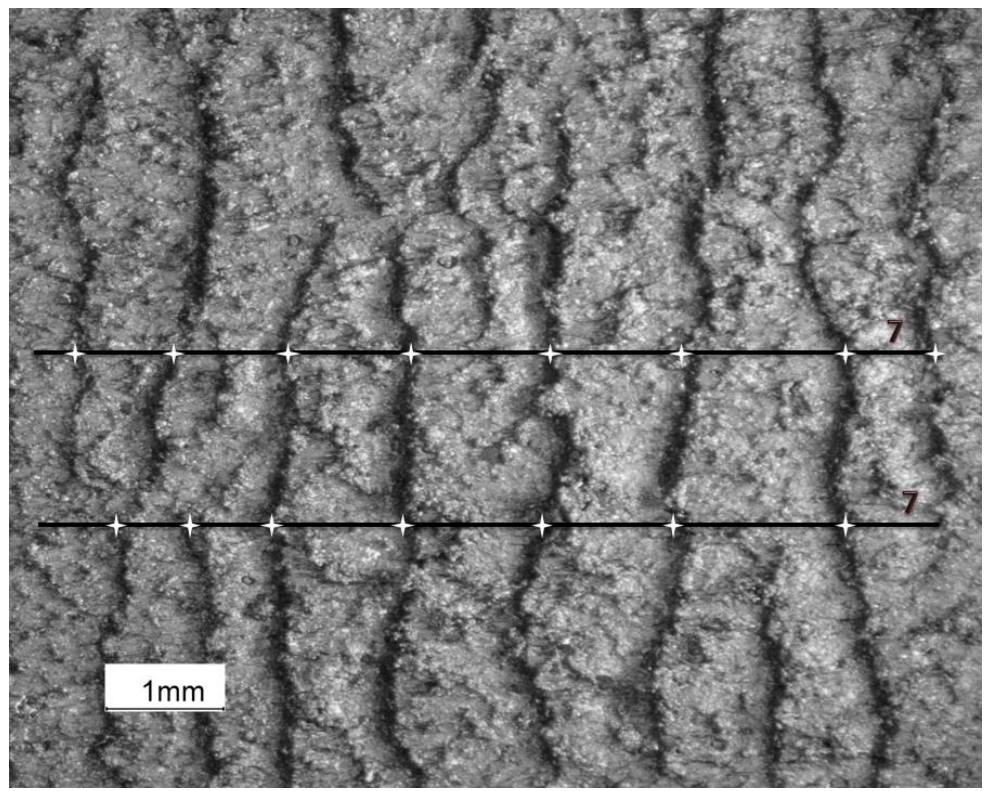

Figura 9 - Amostra RC com os comprimentos de onda demarcados

\section{MATERIAL}

Foram quatro os materiais ensaiados, sendo três exemplares de pneus - pneu comercial para automóveis (RA), pneu verde (RB) e pneu de competição automotiva (RC) - e outro descrito pela norma ASTM [23] (RASTM). A Tabela 1 apresenta as propriedades viscoelásticas de cada borracha, obtidas por tração a $10 \mathrm{~Hz}$ de frequência, com módulo elástico, E', e tangente de delta, $\tan (\delta)$, para diferentes temperaturas. Para a temperatura de $0{ }^{\circ} \mathrm{C}$ não foi possível medir as propriedades do composto RC.

Tabela 1 - Valores de módulo elástico e tangente de delta para cada tipo de borracha

\begin{tabular}{|c|c|c|c|c|c|}
\hline \multirow{2}{*}{\multicolumn{2}{|c|}{ Temperatura $\left({ }^{\circ} \mathrm{C}\right)$}} & \multicolumn{4}{|c|}{ Borracha } \\
\cline { 2 - 6 } 0 & RASTM & RA & RB & RC \\
\hline \multirow{2}{*}{0} & $\mathrm{E}^{\prime}(\mathrm{MPa})$ & 3,58 & 8,2 & 13,39 & - \\
\cline { 2 - 6 } & $\tan (\delta)$ & 0,078 & 0,4 & 0,545 & - \\
\hline \multirow{2}{*}{23} & $\mathrm{E}^{\prime}(\mathrm{MPa})$ & 3,42 & 6,02 & 9,13 & 9,1 \\
\cline { 2 - 6 } & $\tan (\delta)$ & 0,031 & 0,168 & 0,477 & 0,555 \\
\hline \multirow{2}{*}{40} & $\mathrm{E}^{\prime}(\mathrm{MPa})$ & 3,47 & 5,34 & 7,27 & 6,47 \\
\cline { 2 - 6 } & $\tan (\delta)$ & 0,016 & 0,12 & 0,42 & 0,468 \\
\hline \multirow{2}{*}{70} & $\mathrm{E}^{\prime}(\mathrm{MPa})$ & 3,46 & 4,76 & 5,41 & 4,15 \\
\cline { 2 - 6 } & $\tan (\delta)$ & 0,01 & 0,073 & 0,343 & 0,373 \\
\hline
\end{tabular}

A geometria dos corpos de prova variou de acordo com o ensaio no qual o material foi submetido, como ilustra a Figura 10. Para os ensaios de atrito, o corpo de prova em formato de paralelepípedo reto possui 6 por 25 por $76 \mathrm{~mm}$, conforme sua respectiva norma. Já para o ensaio de desgaste e de energia de superfície, o corpo cilíndrico possuía aproximadamente 16 $\mathrm{mm}$ de diâmetro por $6 \mathrm{~mm}$ de altura. Observa-se que todos os corpos de prova foram fornecidos pela Pirelli Pneus do Brasil. 

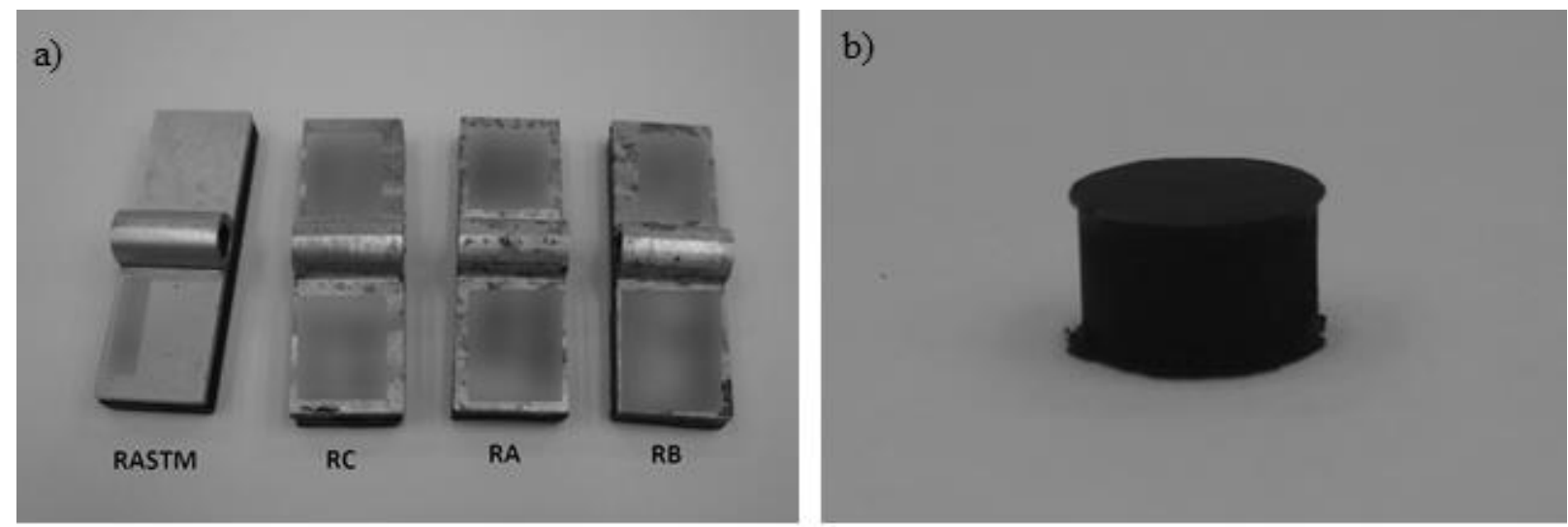

Figura 10 - Amostras para ensaios de pêndulo britânico a) e desgaste/energia de superfície b) (RASTM)

\section{RESULTADOS E DISCUSSÕES}

Os dados dos ensaios de atrito, desgaste, energia de superfície e avaliação do comprimento de onda médio são apresentados na Tabela 2. Observa-se que são apresentados apenas os valores médios dos ensaios para cada composto analisado. Para a avaliação do pavimento, foram utilizadas 7 amostras incluindo superfícies de micro-revestimento e SMA, em diferentes condições de temperatura e lubrificação, gerando cerca de 2.000 ensaios. Para os ensaios de desgaste foram avaliados 4 corpos de prova por composto, totalizando 16 medidas de desgaste. Para os ensaios de gota séssil foram utilizados 4 corpos de prova por composto, totalizando um total de 16 avaliações de energia de superfície. A avaliação do comprimento de onda foi obtida através da análise de 4 comprimentos padrões por composto de borracha, totalizando 16 avaliações do comprimento médio de onda. Os ensaios de atrito contra lixa foram feitos de forma a simular o contato nos ensaios de abrasão, e desta forma, foram feitos sem lubrificação.

Tabela 2 - Dados médios dos ensaios

\begin{tabular}{|c|c|c|c|c|c|}
\hline Borracha & $\begin{array}{l}\text { Comprimento } \\
\text { de onda [mm] }\end{array}$ & $\begin{array}{c}\text { Atrito } \\
\text { (pavimento) }\end{array}$ & $\begin{array}{c}\text { Desgate } \\
{\left[10^{5} \mathrm{~mm}^{3}\right]} \\
\end{array}$ & $\begin{array}{c}\text { Energia de superfície } \\
\text { - Geom }\left[D y{ }^{*} \mathrm{~cm}\right]\end{array}$ & Atrito (lixa) \\
\hline $\mathrm{RC}$ & $4 \quad 1,43$ & 65 & A 3,05 & 27,42 & $\begin{array}{l}495 \\
\end{array}$ \\
\hline RA & 0,65 & 63 & 1,39 & 36,64 & 91 \\
\hline RB & 0,40 & 61 & 1,24 & 33,28 & 90 \\
\hline RASTM & 0,46 & 46 & 0,80 & 34,33 & 86 \\
\hline
\end{tabular}

Inicialmente, analisam-se os dados dos ensaios de atrito, verifica-se que, após análise estatística, os ensaios de atrito, tanto na lixa quanto no pavimento, ordenam as borrachas da mesma forma. $\mathrm{O}$ composto $\mathrm{RC}$, que representa uma borracha utilizada em competições esportivas, apresentou o mais alto valor de atrito, bem como o mais elevado valor de desgaste. Este resultado é esperado para pneus de competição. Os compostos RA e RB, representando um composto comercial padrão e um pneu verde, respectivamente, apresentaram desempenhos similares com relação ao atrito. A borracha RASTM, dado que foi projetada de forma a atender as características de ensaio, e não de um pneu, apresentou um desempenho significativamente diferenciado dos demais. A diferença de atrito dos compostos RA e RB é de apenas 3,1\% para o caso dos ensaios com pavimentos, e 0,1\% para os casos de ensaios tendo a lixa do ensaio de abrasão como contra-corpo. 
Considerando agora os dados de desgaste, RC claramente apresenta os maiores valores. Os compostos intermediários são RA e RB, porém, neste caso, a diferença entre os compostos com relação ao desgaste é maior, atingindo $11 \%$. Considerando conjuntamente o atrito e o desgaste dos compostos, o pneu verde apresenta um desempenho geral elevado, já que mantém boas características de aderência, simultaneamente tendo um desgaste relativamente reduzido. O composto RASTM apresenta o menor desgaste, revelando uma característica desejável a uma borracha para testes: uma durabilidade elevada, resultando em um elevado ciclo de vida para as sapatas usadas no ensaio.

A partir do que foi apresentado na revisão bibliográfica, verifica-se uma correlação entre o desgaste e comprimento de onda, Figura $11 \mathrm{~b}$, o que demonstra que se dois materiais apresentarem na sua superfície ondas de abrasão, pode-se estimar qual material possui maior taxa de desgaste a partir das ondas. Ademais, as correlações obtidas entre atrito e energia de superfície se demonstraram satisfatórias, nos dois casos, tanto em pavimentos, na Figura 11a, quanto em lixa, Figura 11c. Portanto, pode-se estimar o atrito através da energia de superfície. Ressalta-se que os modelos utilizados possuem intercepto nulo forçado, já que, conceitualmente, uma superfície com energia nula geraria um valor de atrito adesivo nulo. Vale lembrar que a energia de superfície está relacionada à parcela adesiva, mas não a parcela histerérica do atrito, desta forma, o atrito adesivo é relevante, porém, uma melhor correlação poderia ser obtida com o atrito histerético.

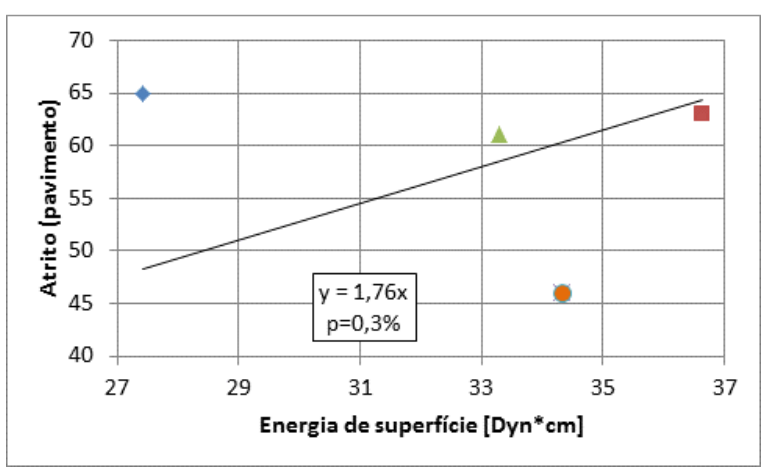

a

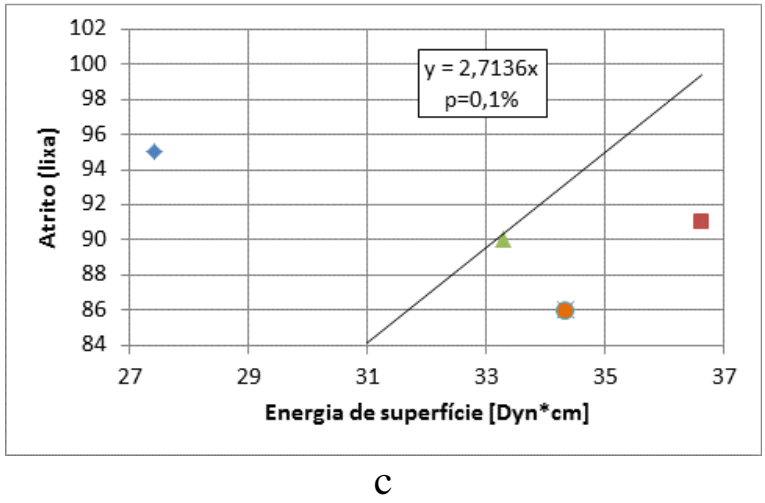

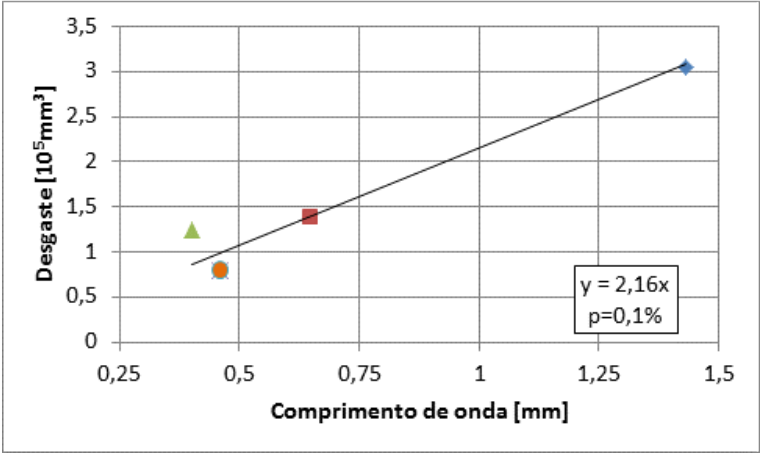

b

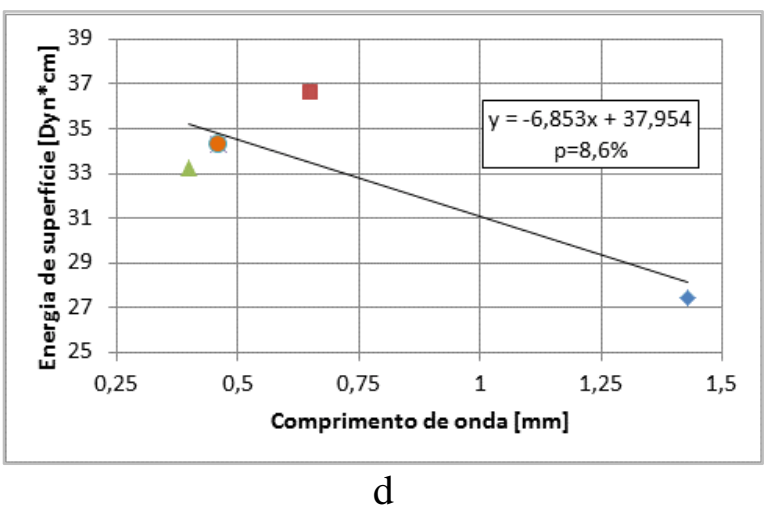

Figura 11 - Gráficos feitos a partir dos resultados apresentados na Tabela 2, onde representa a borracha RC, RA, RB e RASTM.

A relação entre energia de superfície e comprimento de onda não se demonstrou satisfatória. Isto levanta a hipótese de os processos abrasivos serem diferentes em relação a causalidade. Inicialmente, observa-se uma tendência crescente nos compostos RASTM, RA e RB. Já o composto RC apresenta um comportamento diferenciado. Observa-se que a energia de 
superfície está ligada a processos adesivos, logo, o grupo de compostos que apresentou tendência crescente, provavelmente tem o desgaste controlado primordialmente por adesão. Já o composto RC, apresenta uma elevada tangente de delta, ou seja, a parcela histerética é mais relevante. Neste caso, a formação de ondas e o processo de desgaste deve estar mais fortemente controlado pela histerese do material. Isto também justificaria o composto $\mathrm{RC}$ apresentar um maior desvio em relação aos modelos lineares nas figuras Figura 11a e Figura $11 \mathrm{c}$.

\section{CONCLUSÃO}

A partir dos ensaios apresentados, observou-se que o comprimento de onda é uma forma adequada para a previsão do desgaste. Como a formação de ondas ocorre tanto em laboratório, quanto em campo, pode-se avaliar rapidamente o desgaste em campo, comparando-se o comprimento de ondas em diferentes compostos, como forma de se avaliar o desgaste.

Com relação aos ensaios de energia de superfície, observa-se que houve uma correlação significativa com os dados de atrito. Isto revela a contribuição de processos adesivos nos mecanismos de atrito. Além disso, os ensaios de energia de superfície podem revelar o comportamento de um composto com relação ao atrito, desde que a parcela adesiva seja significativa.

A relação entre a energia de superfície e o comprimento de onda não se apresentou estatisticamente relevante. A energia de superfície está ligada ao atrito, já o comprimento de onda, ao desgaste. Para estas variáveis, recomenda-se um estudo mais aprofundado, visto que pode ser possível uma ligação entre os fenômenos de histerese, adesão e desgaste.

\section{AGRADECIMENTOS}

Os autores agradecem à Pirelli Pneus do Brasil, especialmente ao Dr. Argemiro L. de Aragão Costa, pelo apoio durante o desenvolvimento do trabalho e pelo fornecimento dos corpos de prova. Agradecimentos ao Prof. Dr. Amilton Sinatora, do Laboratório de Fenômenos de Superfície, pelo apoio e conhecimentos compartilhados na elaboração deste trabalho. Agradecimentos também à $\mathrm{CNPq}$, pelo apoio e financiamento do projeto Universal 482413/2011-5, focado na inovação de métodos de avaliações da interação pneu-pavimento. Agradecimentos ao Laboratório de Plasmas Tecnológicos da UNESP, especialmente à Profa. Dra. Elidiane C. Rangel, pelo apoio e disponibilidade de realização dos ensaios de energia de superfície.

\section{REFERÊNCIAS}

[1] CALDERÓN, C.; SERVÉN, L. The Effects of Infrastructure Development on Growth and Income Distribution. Working Paper 270, Central Bank of Chile, 2004.

[2] FREEDONIA GROUP. World Tires: Industry Study with Forecasts for 2015 \& 2020. Study 2860. 2012. 478 pp.

[3] THE COMMISSION OF THE EUROPEAN COMMUNITIES. Regulation (EC) No 1222/2009 of the European Parliament and of the Concil of 25 November 2009 on the 
labeling of tyres with respect to fuel efficiency and other essential parameters. Official Journal of the European Union, L342/46. Brussels, 2009.

[4] MOORE, D. F. Principles and Applications of Tribology. Pergamon Press. United Kingdom, 1975.

[5] BRACH, R. M. Adhesion, Hysteresis and the Peak Longitudinal Tire Force. University of Notre Dame, 2006.

[6] ISRAELACHVILI, J. N. Intermolecular and Surface Forces. $2^{\text {nd }}$ edition. Academic Press. London, United Kingdom, 1991.

[7] JOHNSON, K. L. Mechanics of Adhesion, Tribology International - 31, 413 - 418 (1998)

[8] CHENG, W.; DUNN, P. F.; BRACH, R. M. Surface Roughness Effects on Microparticle Adhesion, Indiana, USA, 2002

[9] GROSCH, K. A. The Relation Between the Friction and Visco-Elastic Properties of Rubber, Proceedings of the Royal Society, Welwyn Garden City, Herts, 1962.

[10] JOHNSON, K. L.; KENDALL, K.; ROBERTS, A. D. Surface energy and the contact of elastic solids. Proceedings of the Royal Society of London, Series A, Mathematical and Physical Sciences. Vol 324, n 1558, pp. 301-313. London, Great Britain, 1971.

[11] DELADI, E. L. Static fricton in rubber-metal contacts with application to rubber pad forming processes. Doctoral Thesis, University of Twente. Enschede, The Netherlands, 2006.

[12] FUKAHORI, Y., GABRIEL, P., BUSFIELD, J. J. C. How does rubber truly slide between Schallamach waves and stick-slip motion? Wear, n 269, pp. $854-866$. The Netherlands: 2010.

[13] SCHALLAMACH, A. Abrasion pattern on rubber. Transaction of the institution of Rubber Industry, vol 28. Pp. 256-268. United Kingdom, 1952.

[14] BARQUINS, M. Sliding friction of rubber and Schallamach Waves - A review. Materials Science and Engineering. The Netherlands: 1985.

[15] ASTM, ASTM D5963-10. Standard Test Method for Rubber Property-Abrasion

Resistance: Rotatory Drum Abrader. American Society for Testing and Materials. ASTM International. Pennsylvania: United States, 2010.

[16] MUHR, A. H.; ROBERTS, A. D. Rubber abrasion and wear. Wear, v. 158, n. 1-2, p. 213-228, 1992.

[17] GENT, A. N. Mechanical Properties of Rubber. In: GENT, A. N.; WALTER, J. D. The pneumatic tire. Akron (Ohio, Estados Unidos), 2006. p. 28-76.

[18] FUKAHORI, Y.; YAMAZAKI, H. Mechanism of rubber abrasion. Part III: How is friction linked to fracture in rubber abrasion? Wear, v. 188, n. 1-2, p. 19-26, 1995.

[19] UCHIYAMA, Y.; ISHINO, Y. Pattern abrasion mechanism of rubber. Wear, v. 158, n. 1-2, p. 141-155, 1992.

[20] ASTM, ASTM E303-13. Standard Test Method for Measuring Surface Frictional Properties Using the British Pendulum Tester. American Society for Testing and Materials. ASTM International. Pennsylvania: United States, 2013.

[21] VIEIRA, T. Asphaltic Pavement Surface Analysis and its Effects on the TyrePavement Friction Performance. Master Thesis, University of São Paulo. São Paulo, Brazil, 2014.

[22] FERREIRA, R. P. Comportamento do desgaste abrasivo da borracha butílica submetida a diferentes níveis de força aplicada. Congresso Nacional de Engenharia Mecânica (CONEM). Uberlândia: Brasil, 2014. 
[23] ASTM, ASTM E501-08. Standard Specification for Standard Rib Tire for PAvement Skid-Resistance Tests. American Society for Testing and Materials. ASTM International. Pennsylvania: United States, 2008. 